\title{
PReS-FINAL-2267: Successful treatment of pulmonary arterial hypertension associated with connective tissue disease (PAH-CTD) with combination therapy of sildenafil and ambrisentan: a case report
}

\author{
KI Yamaguchi", M Kishimoto, M Okada \\ From 20th Pediatric Rheumatology European Society (PReS) Congress \\ Ljubljana, Slovenia. 25-29 September 2013
}

\section{Introduction}

Patients with pediatric rheumatic disease rarely develop pulmonary arterial hypertension (PAH), and the expected prognosis had been very poor. With the advancement of oral medicine for PAH in recent years, we can expect better prognosis of these patients. For this purpose, early diagnosis and interventions are essential.

\section{Objectives}

We report on a 14 years old girl suffering from PAH with overlap syndrome (SLE and systemic sclerosis localised type).

\section{Methods}

At age 7, she developed autoimmune hepatitis. She was diagnosed with lupus nephritis (class II + V) from pathological finding and pulmonary hypertension $(\mathrm{PH})$ at age 10, and treated with immunosuppressive therapy (methylprednisolone pulse therapy, cyclophosphamide pulse therapy and mycophenolate mofetil) and home oxygen therapy at night. Comprehensive examination about PH was carried out at age 12 .

\section{Results}

In ultra sound, tricuspid regurgitation and increased pressure gap of tricuspid valve are observed and estimated right ventricular systolic pressure was $60 \mathrm{mmHg}$. In right heart catheterization, mean pulmonary artery

\footnotetext{
Division of Allergy and Rheumatology, St. Luke's International Hospital,
} Tokyo, Japan pressure at rest was $43 \mathrm{mmHg}$ and pulmonary vascular resistance was 711 dyne.sec $10^{-5}$. We had diagnosed her as overlap syndrome (SLE and systemic sclerosis localized type) with $\mathrm{PAH}$, and started combination therapy of sildenafil and ambrisentan. We confirmed the improvement of PAH by right heart catheterization ; mean pulmonary artery pressure $(23 \mathrm{mmHg})$ and pulmonary vascular resistance (296 dyne.sec $\cdot 10^{-5}$ ).

\section{Conclusion}

Considering the obvious limitations of our single case report, we observed a good short term outcome of pediatric PAH-CTD. In order to obtain effects of oral medicine for $\mathrm{PAH}$, it is important to start the intervention at early stage of this disease. It may be useful to plan screening tests (cardiac ultrasonography, pulmonary function test) on a regular basis for patients with pediatric rheumatic disease at high risk of developing PAH.

\section{Disclosure of interest}

None declared.

Published: 5 December 2013

doi:10.1186/1546-0096-11-S2-P257

treatment of pulmonary arterial hypertension associated

with connective tissue disease (PAH-CTD) with combination therapy of

sildenafil and ambrisentan: a case report. Pediatric Rheumatology 201311 (Suppl 2):P257. 